\title{
Renal Excretion of Calcium and Sodium in Acute Nephritis
}

\author{
R. J. WILSON,* M.B., B.SC., M.R.C.P.(LOND., ED.)
}

\begin{abstract}
Gummary : Hypocalciuria was found in the early stages of illness in six patients aged 12 to 30 with acute nephritis. The hypocalciuria does not appear to be due to hypocalcaemia, lowered glomerular filtration rate, or hypoparathyroidism. It is suggested that the hypocalciuria is due in part to decreased intestinal absorption of calcium, though possibly there is also a primary alteration in renal tubular handling of calcium.
\end{abstract}

\section{Introduction}

There have been few reports on urinary calcium output in adults with acute nephritis, though it is well known that urinary calcium excretion is low in chronic nephritis and in the nephrotic syndrome. In children with acute nephritis Boyd, Courtney, and MacLachlan (1926) found hypocalciuria, and this has been confirmed by other workers (Ford, 1931; Meulemeester, 1960 ; Schreiter and Mascher-Koch, 1966).

Sodium retention, with subsequent natriuresis, is common in acute nephritis. Various authors (Walser, 1961 ; Kleeman, Bohannan, Bernstein, Ling, and Maxwell, 1964 ; Phillips and Cooke, 1967) have shown that a close relationship generally exists between urinary sodium and calcium output during acute changes in sodium output.

In this paper further evidence for hypocalciuria in acute nephritis is presented and the relationship between urinary sodium and calcium output in this condition is considered.

\section{Methods}

Features of six cases of acute nephritis are shown in Table I. All had proteinuria, with red cells and casts in the urine, five were oedematous at some time, five were hypertensive on admission, and five had raised antistreptolysin $O$ (A.S.O.) titres.

\begin{tabular}{c|c|c|c|c|c|c}
\multicolumn{8}{c}{ TABLE I.-Details of Six Cases of Acute Nephritis } \\
\hline \begin{tabular}{c|c|c|c|c} 
Case \\
No.
\end{tabular} & $\begin{array}{c}\text { Age in } \\
\text { Years }\end{array}$ & Oedema & $\begin{array}{c}\text { B.P. on } \\
\text { Admission } \\
\text { (mm. Hg) }\end{array}$ & $\begin{array}{c}\text { Protein- } \\
\text { uria }\end{array}$ & $\begin{array}{c}\text { A.S.O. } \\
\text { (units) }\end{array}$ & $\begin{array}{c}\text { Weight } \\
\text { (kg.) }\end{array}$ \\
\hline 1 & 15 & + & $150 / 100$ & Trace & 500 & 54 \\
2 & 30 & + & $155 / 100$ & + & 2,000 & 78 \\
3 & 15 & 0 & $150 / 100$ & + & 500 & 51 \\
4 & 29 & + & $180 / 100$ & + & 1,000 & 52 \\
5 & 12 & + & $160 / 100$ & + & 100 & 26 \\
6 & 26 & + & $140 / 60$ & + & 500 & 58 \\
\hline
\end{tabular}

\section{Metabolic Studies}

Each patient was placed on a diet containing $10 \mathrm{mEq}$ of sodium, and supplemental sodium chloride was provided in capsule form as shown in Table II. The diet of each was constructed to contain about the same amount of calcium as had been taken by the patient before admission to hospital. Successive 24-hour urine collections were made and analysed for volume, sodium, and calcium. Endogenous creatinine clearances were estimated. Fasting samples of blood were drawn without stasis for estimation of plasma calcium and creatinine and of blood urea.

The response to the oral addition of $5 \mathrm{~g}$. of sodium chloride was studied in Cases 2 and 6 . In Cases 4 and 5 oral calcium carbonate $5 \mathrm{~g}$. was added, as indicated in Table II.

* Senior Medical Registrar, Addenbrooke's Hospital, Cambridge.
In Case 3, on day 13, an infusion of disodium edetic acid was given over two hours, in a dosage of $50 \mathrm{mg}$. $/ \mathrm{kg}$., contained in $500 \mathrm{ml}$. of dextrose, with $20 \mathrm{ml}$. of $2 \%$ procaine added.

TABLE II.-Urinary Excretion of Calcium and Sodium; Relation to

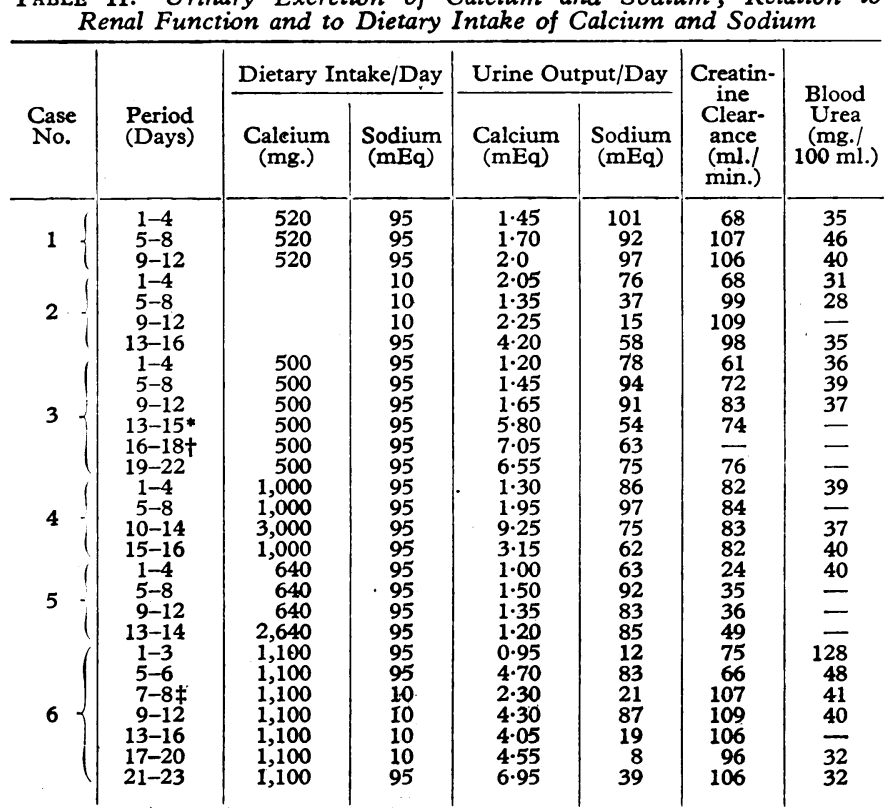

* Case 3, day 13, infusion of edetic acid.

t Case 3, day 16, infusion of calcium gluconate containing $625 \mathrm{mg}$. calcium and ₹ Case 6 , fludrocortisone $5 \mathrm{mg}$. on days 7 and 8 .

The infusion contained $5 \mathrm{mEq}$ of sodium. On day 16 an infusion of calcium gluconate was given over four hours: $80 \mathrm{ml}$. of $10 \%$ calcium gluconate was given in $440 \mathrm{ml}$. of normal saline ( $68 \mathrm{mEq}$ of sodium chloride).

On days 7 and 8 , in Case 6 , oral fludrocortisone $5 \mathrm{mg}$. daily was given. Informed consent was obtained for these procedures in every case.

Plasma and urinary sodium and calcium were measured with an Eppendorf flame photometer and creatinine by an AutoAnalyzer technique.

\section{Results}

A summary of the results is shown in Table II. It will be seen that in all cases urinary calcium excretion was low during the early stage of acute nephritis despite only moderate reduction in creatinine clearance, and this hypocalciuria obtained whether the patient was in a phase of sodium retention (Case 6), in or near sodium balance (Cases $1,3,4$, and 5), or in a natriuretic phase (Case 2). Urinary calcium excretion, however, did show some relation to urinary sodium excretion. In Case 2 it will be seen that as urinary sodium output fell there was an initial fall in urinary calciutm and a later rise.

With "recovery" of the patients creatinine clearances in most cases rose to normal or near normal levels, and urinary calcium tended to rise a little but remained well below normal levels. 
When the oral intake of salt was raised by $85 \mathrm{mEq}$ in Cases 2 and 6 each showed an acute rise in both urinary sodium and calcium excretion.

In Case 6, during a spontaneous natriuresis, urinary calcium rose sharply but did not later fall when the urinary sodium fell in response to a $10-\mathrm{mEq}$ sodium intake.

Oral calcium carbonate $5 \mathrm{~g}$./day ( $2 \mathrm{~g}$. of calcium) was given in Cases 4 and 5 . In Case 4 this led to an immediate pronounced rise in urinary calcium to within the normal range. In Case 5, however, no rise in urinary calcium occurred. It may bo relevant that the creatinine clearance in Case 4 was $83 \mathrm{ml}$./minute, while in Case 5 it was only $49 \mathrm{ml} . / \mathrm{minute}$ at the time of administration of calcium carbonate.

In Case $3208 \mathrm{mg}$. of calcium was excreted in the 24 hours that an infusion containing $625 \mathrm{mg}$. of calcium was given. Urinary calcium subsequently remained raised as compared with preinfusion values, despite a return of plasma calcium to normal within 24 hours. In Case 3 the plasma calcium response to edetic acid infusion (Jones and Fourman, 1963) was normal.

Except during infusion of edetic acid or calcium gluconate plasma calcium was within normal limits (mean $9.3 \mathrm{mg}$./ $100 \mathrm{ml}$.) and showed no systematic variations. No measurements of ultrafilterable calcium or of faecal calcium were made.

In three cases (Nos. 1, 5, and 6), at intervals of nine months, four months, and three years respectively after the onset of acute nephritis, urinary calcium was 134, 104, and $149 \mathrm{mg}$./ 24 hours.

\section{Discussion}

Though hypocalciuria in chronic nephritis and in nephrosis (Jones, Peters, Morgan, Coles, and Mallick, 1967) is well documented there have been few studies on urinary calcium in acute nephritis, and they have all been on children (Boyd et al., 1926 ; Ford, 1931; Meulemeester, 1960 ; Schreiter and MascherKoch, 1966). In none of these studies are data on blood urea or glomerular filtration rate given. In the six cases of acute nephritis reported here urinary calcium is low in all during the early stages of the illness despite a normal serum calcium and only moderate reduction in creatinine clearance. With the passage of time and in association with a rise in the creatinine clearance to normal or near normal values urinary calcium tends to rise. The situation is in marked contrast to that in chronic nephritis, where hypocalciuria is associated with a pronounced reduction in glomerular filtration rate, and often with hypocalcaemia. Earlier workers (Meulemeester, 1960 ; Schreiter and Mascher-Koch, 1966) have also found hypocalciuria early in acute nephritis a constant feature, and it may become a useful point in establishing the diagnosis. Schreiter and Mascher-Koch (1966) showed that in acute pyelonephritis in children urinary calcium excretion is normal.

An association between the urinary excretion of calcium and sodium has been described in dogs (Walser, 1961), in healthy individuals (King, Jackson, and Ashe, 1964 ; Kleeman et al., 1964), and in patients with idiopathic hypercalciuria (Phillips and Cooke, 1967).

From Table II it is seen that hypocalciuria persists at all levels of urinary sodium. During acute changes in urinary sodium, however, a corresponding change in urinary calcium is seen. Thus the addition of oral $85 \mathrm{mEq}$ of sodium chloride in Cases 2 and 6 led to an immediate increase in urinary calcium. In Case 2, as urinary sodium fell in response to $10 \mathrm{mEq}$ of sodium chloride intake, urinary calcium first fell $10 \mathrm{mEq}$ of sodium and then rose. The initial Walser and others, while the later rise is seen also in normal individuals (Wilson and Mills, unpublished).

In Case 6 it is seen that with the onset of a sodium diuresis urinary calcium rose markedly. When fludrocortisone $5 \mathrm{mg}$. was given for two days, both urinary sodium and calcium fell, though the glomerular filtration rate rose markedly. With withdrawal of fludrocortisone, urinary sodium and calcium both rose again. There was little change in urinary calcium in Case 6 during adaptation to a $10-\mathrm{mEq}$ sodium intake, and it appears that in this patient, and to a less extent in others, fluctuations in urinary calcium with urinary sodium are partially obscured by a tendency for the urinary calcium to rise with time, concurrent with a rise in creatinine clearance.

The mechanisms of production of hypocalciuria in chronic nephritis are uncertain, but factors include a low glomerular filtration rate, a tendency to lowered ultrafilterable plasma calcium (Better, Kleeman, Gonick, Varrady, and Maxwell, 1967), lowered intestinal absorption of calcium in association with a relative resistance to vitamin D (Stanbury and Lumb, 1962), and altered metabolism of vitamin D (Avioli, Birge, Lee, and Slatopolsky, 1968). Obligatory solute diuresis and raised load of complexed calcium tend to enhance calcium excretion (Better et al., 1967). Whether renal tubular handling of calcium is altered appears uncertain.

In acute nephritis urinary calcium is low despite a normal plasma calcium and normal or near normal glomerular filtration rate. No data are available on plasma ultrafilterable calcium or on the urinary excretion of calcium complexing ions. Certainly, in the presence of a chelating agent, edetic acid, the urinary excretion of calcium rose in Case 3. The hypocalciuria of acute nephritis does not seem due to hypoparathyroidism, for plasma calcium is normal and the response to edetic acid (in one patient) was normal.

In chronic nephritis decreased intestinal absorption is associated with decreased sensitivity to vitamin $D$ (Stanbury and Lumb, 1962). Bell and Bartter (1964) studied one patient with sarcoidosis who happened to develop acute nephritis. They found that with the onset of nephritis there developed hypocalcaemia and hypocalciuria, while intestinal calcium absorption fell and was not increased by vitamin D. With recovery from nephritis, calcium hyperabsorption again occurred. This suggests that hypocalciuria in acute nephritis may be due in part to a decreased intestinal absorption of calcium, though the possibility remains that there is also a primary change in the renal tubular handling of calcium. The response to intravenous and oral calcium respectively in Cases 3 and 4 does support the view that decreased intestinal absorption of calcium is a major factor in the hypocalciuria of acute nephritis, and the failure of response in Case 5 might have been due either to a greater impairment of calcium absorption (as this patient had the greatest reduction in creatinine clearance) or to the fact that the calcium carbonate was given for only two days. In this respect it is interesting that Clarkson, McDonald, and de Wardener (1966) found an increase both in calcium absorbed and in urinary calcium excreted when large quantities of oral calcium carbonate or citrate were given to people in chronic renal failure.

If there is indeed a defect in calcium absorption from the gut in both acute nephritis and chronic nephritis it suggests that there may be a renal factor contributing to the control of intestinal calcium absorption.

I am grateful to Dr. D. Gairdner for permission to study Case 5, and to Professor I. H. Mills, department of investigative medicine, University of Cambridge, for permission to study the other five patients.

\section{REFERENCES}

Avioli, L. V Birge, S., Lee, S. W., and Slatopolsky, E. (1968). Fournal Avioli, L. Clinical Investigation, 47,2239 .

Bell, N. H., and Bartter, F. C. (1964). Annals of Internal Medicine, 61,

702 .
Better, O. S., Kleeman, C. R., Gonick, H. C., Varrady, P. D., and Maxwell, M. H. (1967). Israel Fournal of Medical Sciences, 3, 60 Boyd, G. L., Courtney, A. M., and MacLachlan, I. F. (1926). American fournal of Diseases of Children, 32, 29. 
Clarkson, E. M., McDonald, S. J, and de Wardener, H. E. (1966). Clinical Science, 30, 425 .

Ford, F. J. (1931). Archives of Diseases in Childhood, 6, 209.

Jones, K. H., and Fourman, P. (1963). Lancet, 2, 119.

Jones, J. H., Peters, D. K., Morgan, D. B., Coles, G. A., and Mallick, N. P. (1967). Quarterly fournal of Medicine, 36, 301.

King, J. S., Jackson, R., and Ashe, B. (1964). Investigative Urology, 1,
Kleeman, C. R., Bohannan, J., Bernstein, D., Ling, S., and Maxwell, M. H. (1964). Proceedings of the Society of Experimental Biology and Medicine, 115, 29.

Meulemeester, F. de (1960). Archives française de Paediatrie, 17, 647. W

Phillips, M. J., and Cooke, J. N. C. (1967). Lancet, 1, 1354.

Schreiter, G., and Mascher-Koch, M. (1966). Monatsschrif: fïr Kinderheilkunde, 114, 432.

Stanbury, S. W., and Lumb, G. A. (1962). Medicine, 41, i.

Walser, M. (1961). American fournal of Physiology, 200, 1099.

\title{
Handling of Induced Hypercalcaemia in Hyperthyroidism
}

\author{
P. LIM,* M.B., B.CHIR., M.R.C.P. ; E. JACOB, $\dagger$ PH.D. ; O. T. KHOO, $\ddagger$ M.D., F.R.C.P.ED., F.R.A.C.P.
}

\begin{abstract}
Summary : The mean serum calcium of 13 hyperthyroid patients was found to be significantly higher than that of controls matched for sex and age, though none of the patients' values were outside the normal range. Nevertheless, these patients responded very promptly to hypercalcaemia (induced by an intravenous calcium load), and their serum calcium returned to normal much more rapidly compared with the matched controls. There was also increased retention of intravenous calcium load, possibly owing to increased calcitonin production. Calcium infusion may be useful in treating bone diseases in which increased bone resorption exceeds bone accretion.
\end{abstract}

\section{Introduction}

Hypercalcaemia in hyperthyroidism not associated with hyperparathyroidism, though rare, has been reported (Epstein et al., 1958 ; Kleeman et al., 1958). Adams et al. (1967) found the mean serum calcium of hyperthyroid patients to be higher $(P<0.01)$ than that of a group of normal subjects matched for sex and age, and since the mean serum albumin concentration of these patients was less $(P<0.001)$ than that of the normal subjects these workers deduced that the serum concentration of the biologically important ionized calcium in hyperthyroid patients was greater than normal. This was confirmed by Frizel et al. (1967), who directly measured serum ionized calcium in hyperthyroid patients.

In view of the established presence of hypercalcaemia in hyperthyroidism we have undertaken a study of the homoeostatic control of plasma calcium in this condition. Adams et al. (1967) have studied the response to induced hypocalcaemia. In the present investigation the response to induced hypercalcaemia is investigated.

\section{Materials and Methods}

(1) In 13 patients (seven males, six females) with untreated hyperthyroidism established clinically and by radioactive iodine uptake, changes in serum calcium were studied following an infusion of calcium. The patients were aged from 16 to 58 years and had no evidence of any concomitant illness. They were matched for sex and age with 13 normal controls.

Patients and controls were each given an intravenous calcium load in the form of calcium gluconate; blood was taken without venous stasis for serum calcium estimation just before infusion

* Lecturer in Clinical Medicine, University of Singapore. + Biochemist, General Hospital, Singapore.

$¥$ Professor of Clinical Medicine, University of Singapore. (zero hour) and at 4, 8, 12, and 24 hours after the start of infusion. Both the zero-hour and 24-hour specimens were of taken with the subjects fasted overnight. The amount of calcium gluconate used was calculated on the basis of body $\vec{\omega}$ weight (15 mg. of elemental calcium per kg. body weight) and was infused, diluted in $500 \mathrm{ml}$. of $5 \%$ dextrose, evenly $N$ over four hours. All subjects were put on a $600-\mathrm{mg}$. calcium diet during the test. Serum calcium was estimated in duplicate $\mathbb{D}$ with the atomic absorption spectrophotometer (SP 90, Unicam); the error between duplicate estimations never $\frac{7}{0}$ exceeded $0.1 \mathrm{mg} . / 100 \mathrm{ml}$.

The overall assessment of each subject's response to hyper- $\overrightarrow{\mathscr{\theta}}$ calcaemia was made by estimating the tolerance area. This is the area below the straight lines joining the five points on $\square$ the time versus serum calcium graph (Fig. 1), above the horizontal line at the preinfusion serum calcium value. The area is represented by the formula:

$$
\text { Area }=\left(b+c+2 d+\frac{3}{2} e-5 \frac{1}{2} a\right) \text { units }
$$

where " $a$ " is serum calcium at zero hour, " $b$ " at fourth hour, $\frac{0}{3}$ " $c$ " at eighth hour, " $d$ " at twelfth hour, and "e" at twenty-fourth hour. Where b, c, d, or e is less than a a correction factor will have to be applied to the formula. Thus, if $e$ is less than a the formula is modified as follows:

$$
\text { Area }=b+c+2 d+\frac{3}{2} e-5 \frac{1}{2} a+\frac{3(a-e)^{2}}{2(d-e)} \text { units }
$$

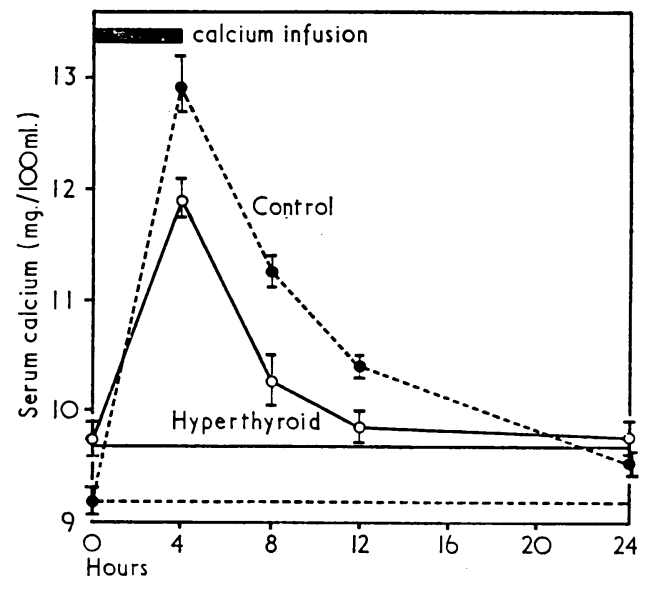

FIG. 1.-Effect on serum calcium of an infusion of calcium, shown as mean \pm S.E. of mean for hyper. thyroid patients and controlled subjects.

(2) In another group of six untreated hyperthyroid patients and six normal controls a test of calcium retention was carried out. Patients were put on a low $(150 \mathrm{mg}$.) calcium diet for four days, and urine was collected daily for estimation of 